\title{
Semi Analytical Approach for Establishing the Two Real Roots of Sextic Polynomial
}

\section{Shebl SA*}

Engineering Mathematics and Physics Department, Faculty of Engineering, Alexandria University, Egypt

\begin{abstract}
Zeros of polynomial equations are analytically hard to be determined beyond the special cases of the quartic equations. Under some particular conditions, quintic and sextic polynomial equations may be solved iteratively.

This paper presents analytical-graphical solution for accomplishing zeros of particular sextic polynomial equation of two real zeros. The concerned polynomial has been modeled geometrically as the radical problem in geodesy which is the geodetic height of a point on the terrain surface of the earth. The earth's model to be adopted is the triaxial ellipsoidal surface.
\end{abstract}

The achieved solution may be utilized as initial values for a convenient and convergent iterative process.

Keywords: Sextic; Triaxial ellipsoid; Mongean projection; Geodetic height; Umbilic points

\section{Introduction}

For a long time, solutions of polynomial equations of higher order have been dealt with either graphically or analytically [1]. The works of Abel and Galois have shown that the general polynomial equations of degree higher than the fourth cannot be solved in radicals [2]. While Abel published the proof of impossibility of solving these equations (Abel's impossibility theorem), Galois gave a more rigorous proof using the group theory. This does not mean that there is no algebraic solution to the general polynomial equations of degree five and above [3]. In fact these equations are solved algebraically by employing symbolic coefficients: the general quintic is solved by using the Bring radicals, while the general sextic can be solved in terms of Kampe de Feriet functions [4].

Under certain limited conditions concerning the coefficients and roots, Kulkarni described a method to decompose the given sextic equation into two cubic polynomials as factors. The cubic polynomials are then equated to zero and solved to obtain the six roots of the sextic equation in radicals [5].

This paper introduces a straightforward and accurate solution for sextic polynomial equation of two real roots involving an analyticalgraphical analysis. The related polynomial characterizes the geometrical model of a common problem in geodesy which is the geodetic height [6]. Therefore, we pursue the solution of sextic polynomial equation of two real roots originated accordingly from the geodetic height problem.

Such a model symbolizes the coordinates of two foot points of the two normals from a point on the irregular surface of the earth (terrain) to the triaxial ellipsoidal surface as the earth's model [7]. This has been yielded two curves characterize the locii of the traces of the normals from the terrain point to the surface circular sections whose intersections are the desired two foot points.

The graphical solution was granted and considered to identify such locii and, consequently, their intersections whose coordinates may be exploited as a preliminary estimate of initial values when iterative process is considered.

\section{Methodology}

The sextic polynomial of interest takes the form:

$$
\sum^{6} a_{n} t^{n}=0
$$

and, according to Figure 1, considering a triaxial ellipsoid surface's center as the coordinate system's origin, aligning $z$-axis to the polar axis direction and $\mathrm{x}$ - axis to the east direction, then equation of the surface may be expressed as:

$$
\left(\mathrm{X}^{2} / \mathrm{a}^{2}\right)+\left(\mathrm{Y}^{2} / \mathrm{b}^{2}\right)+\left(\mathrm{Z}^{2} / \mathrm{c}^{2}\right)=1
$$

Such reference surface has dimensions (a) along the semi-major axis (x-axis), (b) along the semi-minor axis (y-axis) and (c) along the polar axis (z-axis), and $\mathrm{a}>\mathrm{b}>\mathrm{c}$ (Figure 1 ).

There are six normals from E to the reference surface [6-8], four of which are imaginary and two are real. The two normals from the terrain point $\mathrm{E}\left(\mathrm{X}_{\mathrm{E}}, \mathrm{Y}_{\mathrm{E}}, \mathrm{Z}_{\mathrm{E}}\right)$, Figure 2, to the reference surface has two foot points $P$ of coordinates $\left(X_{p}, Y_{p}, Z_{p}\right)$, one of them gives the minimum distance from $\mathrm{E}$ to the surface, i. e. the geodetic height [6].

The evaluation of the model relies absolutely on the location of the terrain point $\mathrm{E}$ and the size of the reference surface as well (Figure 2).

The foot points $\mathrm{P}$ may be located graphically as the points of intersection of two curves $\mu$ and $\eta$, each of which is the locus of the normals from $E$ to a set of circular sections of the surface. The technique traced for constructing $\mu, \eta$. Coordinates of $P$ is utilized as follows.

In Figure 2, PE is the normal from $\mathrm{E}$ to the surface, and then the parametric coordinates of $\mathrm{P}$ are:

$$
\begin{aligned}
& \mathrm{X}_{\mathrm{P}}=\mathrm{X}_{\mathrm{E}} / \mathrm{t} \\
& \mathrm{Y}_{\mathrm{P}}=\mathrm{Y}_{\mathrm{E}}\left(1-\mathrm{e}_{1}^{2}\right) /\left(\mathrm{t}-\mathrm{e}_{1}^{2}\right)
\end{aligned}
$$

*Corresponding author: Shebl SA, Engineering Mathematics and Physics Department, Faculty of Engineering, Alexandria University, Alexandria, 2438, Egypt, Tel: 2035910052; E-mail: sshebl@hotmail.com

Received September 01, 2015; Accepted September 07, 2015; Published September 09, 2015

Citation: Shebl SA (2015) Semi Analytical Approach for Establishing the Two Real Roots of Sextic Polynomial. J Appl Computat Math 4: 254. doi:10.4172/21689679.1000254

Copyright: (C) 2015 Shebl SA. This is an open-access article distributed under the terms of the Creative Commons Attribution License, which permits unrestricted use, distribution, and reproduction in any medium, provided the original author and source are credited. 


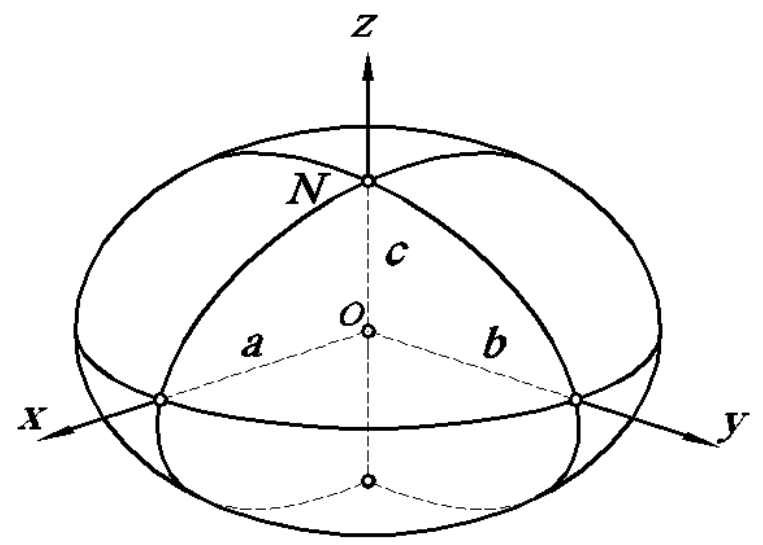

Figure 1: Coordinate Reference System.

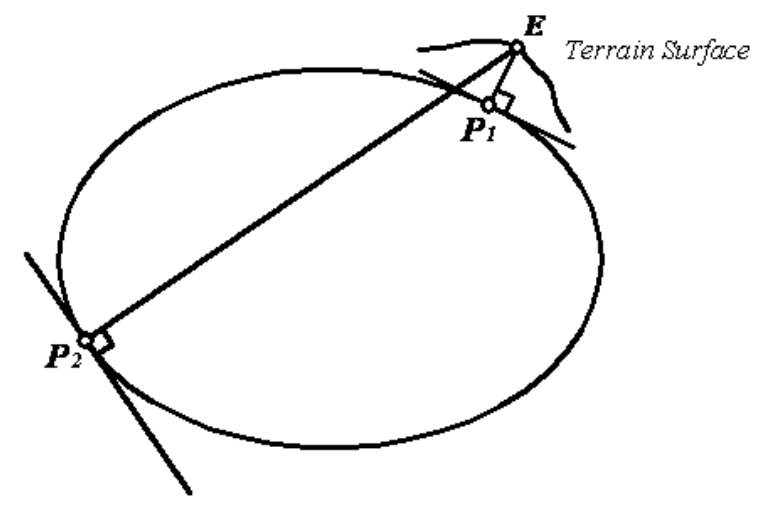

Figure 2: Geodetic Height Model.

$$
\mathrm{Z}_{\mathrm{P}}=\mathrm{Z}_{\mathrm{E}}\left(1-\mathrm{e}_{2}^{2}\right) /\left(\mathrm{t}-\mathrm{e}_{2}^{2}\right)
$$

Where, when applying "3" to "2", t stands for the roots of "1", $e_{1}$ is the equatorial eccentricity, and $e_{2}^{2}$ is the polar eccentricity, where:

$$
\mathrm{e}_{1}^{2}=1-\left(\mathrm{b}^{2} / \mathrm{a}^{2}\right)
$$

and:

$$
\mathrm{e}_{2}^{2}=1-\left(\mathrm{c}^{2} / \mathrm{a}^{2}\right)
$$

Substituting these coordinates into the equation of the surface (Equation "2") and comparing the coefficients of the resulting equation with the coefficients of "1", then:

$$
\begin{aligned}
\mathrm{a}_{6} & =1 \\
\mathrm{a}_{5} & =-2 \mathrm{e}_{1}^{2}-2 \mathrm{e}_{2}^{2} \\
\mathrm{a}_{4} & =-\mathrm{F}^{2}+\mathrm{e}_{2}{ }^{4}+\mathrm{e}_{1}{ }^{4}+4 \mathrm{e}_{1}{ }^{2} \mathrm{e}_{2}{ }^{2}-\mathrm{G}^{2}-\mathrm{e}_{1}{ }^{2} \mathrm{G}^{2}-\mathrm{H}^{2}+\mathrm{e}_{2}{ }^{2} \mathrm{H}^{2} \\
\mathrm{a}_{3} & =2 \mathrm{e}_{2}{ }^{2} \mathrm{~F}^{2}+2 \mathrm{e}_{1}{ }^{2} \mathrm{~F}^{2}-2 \mathrm{e}_{1}{ }^{2} \mathrm{e}_{2}{ }^{4}-2 \mathrm{e}_{1}{ }^{4} \mathrm{e}_{2}{ }^{2}+2 \mathrm{e}_{2}{ }^{2} \mathrm{G}^{2}-2 \mathrm{e}_{1}{ }^{2} \mathrm{e}_{2}{ }^{2} \mathrm{G}^{2}+2 \\
\mathrm{e}_{1}{ }^{2} \mathrm{H}^{2} & -2 \mathrm{e}_{1}^{2} \mathrm{e}_{2}{ }^{2} \mathrm{H}^{2}
\end{aligned}
$$

$\mathrm{a}_{2}=-\mathrm{e}_{2}{ }^{4} \mathrm{~F}^{2}-\mathrm{e}_{1}{ }^{4} \mathrm{~F}^{2}-4 \mathrm{e}_{1}{ }_{1} \mathrm{e}_{2}{ }^{2} \mathrm{~F}^{2}+\mathrm{e}_{1}{ }^{4} \mathrm{e}_{2}{ }^{4}-\mathrm{e}_{2}{ }^{4} \mathrm{G}^{2}+\mathrm{e}_{1}{ }^{2} \mathrm{e}_{2}{ }^{4} \mathrm{G}^{2}-\mathrm{e}_{1}{ }^{4} \mathrm{H}^{2}$ $+\mathrm{e}_{1}^{4} \mathrm{e}_{2}^{2} \mathrm{H}^{2}$

$\mathrm{a}_{1}=2 \mathrm{e}_{1}^{2} \mathrm{e}_{2}^{4} \mathrm{~F}^{2}+2 \mathrm{e}_{1}^{4} \mathrm{e}_{2}^{4} \mathrm{~F}^{2}$

$\mathrm{a}_{0}=-\mathrm{e}_{1}^{4} \mathrm{e}_{2}^{4} \mathrm{~F}^{2}$ where:

$$
\begin{aligned}
& \mathrm{F}^{2}=\mathrm{X}_{\mathrm{E}}{ }^{2} / \mathrm{a}^{2} \\
& \mathrm{G}^{2}=\mathrm{Y}_{\mathrm{E}}{ }^{2} / \mathrm{b}^{2} \\
& \mathrm{H}^{2}=\mathrm{Z}_{\mathrm{E}}{ }^{2} / \mathrm{c}^{2}
\end{aligned}
$$

Solving "6" to "15" in terms of $\mathrm{a}_{0}, \mathrm{a}_{1}, \mathrm{a}_{3}, \mathrm{a}_{4}$ and $\mathrm{a}_{5}$ yields:

$$
\begin{aligned}
& \mathrm{e}_{1}^{2}=-\left(\mathrm{a}_{5} / 4\right)-\varepsilon \\
& \mathrm{e}_{2}^{2}=-\left(\mathrm{a}_{5} / 4\right)+\varepsilon \\
& \mathrm{F}^{2}=-\mathrm{a}_{1}^{2} /\left(\mathrm{a}_{0} \mathrm{a}_{5}^{2}\right) \\
& \mathrm{G}^{2}=\left[\alpha /\left(4\left(1-\mathrm{e}_{1}^{2}\right)\right)\right]+\left[\beta /\left(4 \varepsilon\left(1-\mathrm{e}_{1}^{2}\right)\right)\right] \\
& \mathrm{H}^{2}=\left[\alpha /\left(4\left(1-\mathrm{e}_{2}^{2}\right)\right)\right]-\left[\beta /\left(4 \varepsilon\left(1-\mathrm{e}_{2}^{2}\right)\right)\right]
\end{aligned}
$$

where:

$$
\begin{aligned}
& \varepsilon=\left[\left(a_{5}^{2} / 16\right)-\left(a_{0} a_{5} / a_{1}\right)\right]^{1 / 2} \\
& \alpha=\left(2 a_{1}^{2} /\left(a_{0} a_{5}^{2}\right)\right)+\left(a_{5}^{2} / 2\right)+\left(4 a_{0} a_{5} / a_{1}\right)-2 a_{4} \\
& \beta=-\left(a_{4} a_{5} / 2\right)+a_{3}-\left(a_{1}^{2} /\left(2 a_{0} a_{5}\right)\right)+a_{5}^{3} / 8
\end{aligned}
$$

Assuming a reasonable value for $a$, then values of $b$ and $c$ can be determined in terms of the polynomial coefficients from "16" and " 17 ", as:

$$
\begin{aligned}
& \mathrm{b}=\mathrm{a}\left(1+\varepsilon+\mathrm{a}_{5} / 4\right)^{1 / 2} \\
& \mathrm{c}=\mathrm{a}\left(1-\varepsilon+\mathrm{a}_{5} / 4\right)^{1 / 2}
\end{aligned}
$$

Also, values of $\mathrm{X}_{\mathrm{E}}, \mathrm{Y}_{\mathrm{E}}$, and $\mathrm{Z}_{\mathrm{E}}$ can be obtained in terms of the polynomial coefficients from "13" through "15".

Now, to obtain the desired roots $t$ (from Equation "3"), we seek the foot point $\mathrm{P}\left(\mathrm{X}_{\mathrm{P}}, \mathrm{Y}_{\mathrm{P}}, \mathrm{Z}_{\mathrm{P}}\right)$ which, as previously mentioned, may be located graphically as the points of intersection of two curves $\mu$ and $\eta$, each of which is the locus of points of intersection between normals from $E$ to a set of circular sections, with these sections. The technique traced for constructing $\mu, \eta$ and coordinates of $\mathrm{P}$ is utilized as follows.

Figure 3 displays a significant aspect associated with the triaxial ellipsoidal surface that is the circular sections. There exist two sets of such sections [8]. The first set of these sections is generated as the intersections of the surface with a set of parallel planes whose equations are (Figure 3):

$$
\mathrm{Z}=(\mathrm{X}-\delta)\left[\mathrm{c}^{2}\left(\mathrm{a}^{2}-\mathrm{b}^{2}\right) /\left(\mathrm{a}^{2}\left(\mathrm{~b}^{2}-\mathrm{c}^{2}\right)\right)\right]^{1 / 2}
$$

where $\delta$ is the length along $x$-axis traced by the planes (Figure 4 ). These planes are parallel to planes tangent to the surface at the umbilic points $U_{1}$ and $U_{2}$ whose coordinates are (Figure 4):

$$
\left(U_{1}, U_{2}\right)=\left( \pm a\left[\left(a^{2}-b^{2}\right) /\left(a^{2}-c^{2}\right)\right]^{1 / 2}, 0, \mp c\left[\left(b^{2}-c^{2}\right) /\right.\right.
$$
$\left.\left.\left(a^{2}-c^{2}\right)\right]^{1 / 2}\right)$ is:

The locus of these centers is a line joining $U_{1}$ and $U_{2}$ and its equation

$$
\mathrm{Z}=-\mathrm{X}\left[\mathrm{c}^{2}\left(\mathrm{~b}^{2}-\mathrm{c}^{2}\right) /\left(\mathrm{a}^{2}\left(\mathrm{a}^{2}-\mathrm{b}^{2}\right)\right)\right]^{1 / 2}
$$

and the centers of the circles are:

$\mathrm{C}_{1}=\left( \pm \delta\left(\mathrm{a}^{2}-\mathrm{b}^{2}\right) /\left(\mathrm{a}^{2}-\mathrm{c}^{2}\right), 0, \mp \delta \mathrm{c}\left(\mathrm{a}^{2}-\mathrm{b}^{2}\right)^{1 / 2}\left(\mathrm{~b}^{2}-\mathrm{c}^{2}\right)^{1 / 2} /\right.$ $\left.\left(\mathrm{a}\left(\mathrm{a}^{2}-\mathrm{c}^{2}\right)\right)\right)$

Similarly, the other set of the circular sections are generated by intersecting the surface with the parallel planes of equations: 


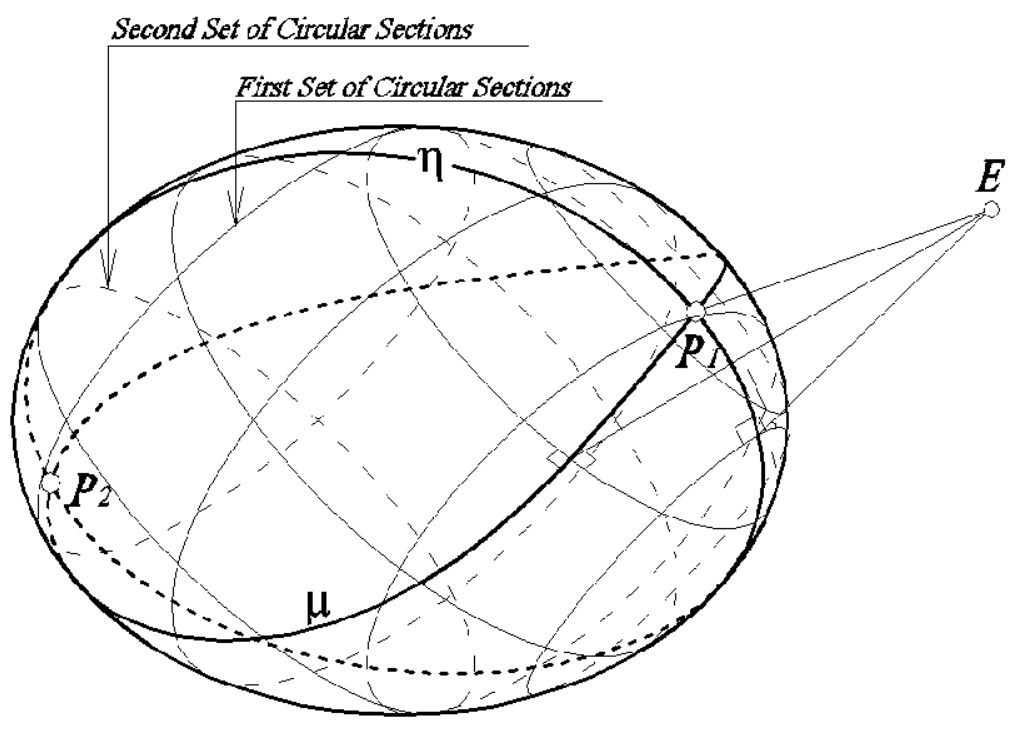

Figure 3: Circular Sections.

$$
\mathrm{Z}=-(\mathrm{X}-\delta)\left[\mathrm{c}^{2}\left(\mathrm{a}^{2}-\mathrm{b}^{2}\right) /\left(\mathrm{a}^{2}\left(\mathrm{~b}^{2}-\mathrm{c}^{2}\right)\right)\right]^{1 / 2}
$$

whose corresponding umbilics $\mathrm{U}_{3}$ and $\mathrm{U}_{4}$ are of coordinates:

$\left(\mathrm{U}_{3}, \mathrm{U}_{4}\right)=\left( \pm \mathrm{a}\left[\left(\mathrm{a}^{2}-\mathrm{b}^{2}\right) /\left(\mathrm{a}^{2}-\mathrm{c}^{2}\right)\right]^{1 / 2}, 0, \pm \mathrm{c}\left[\left(\mathrm{b}^{2}-\mathrm{c}^{2}\right) /\right.\right.$ $\left.\left.\left(a^{2}-c^{2}\right)\right]^{1 / 2}\right)$

The locus of these centers is a line joining $\mathrm{U}_{3}$ and $\mathrm{U}_{4}$ whose equation is:

$$
\mathrm{Z}=\mathrm{X}\left[\mathrm{c}^{2}\left(\mathrm{~b}^{2}-\mathrm{c}^{2}\right) /\left(\mathrm{a}^{2}\left(\mathrm{a}^{2}-\mathrm{b}^{2}\right)\right)\right]^{1 / 2}
$$

and the centers of the circles are: $\left.\left.c^{2}\right)\right)$ )

$\mathrm{C}_{2}=\left( \pm \delta\left(\mathrm{a}^{2}-\mathrm{b}^{2}\right) /\left(\mathrm{a}^{2}-\mathrm{c}^{2}\right), 0, \pm \delta \mathrm{c}\left(\mathrm{a}^{2}-\mathrm{b}^{2}\right)^{1 / 2}\left(\mathrm{~b}^{2}-\mathrm{c}^{2}\right)^{1 / 2} /\left(\mathrm{a}\left(\mathrm{a}^{2}-\right.\right.\right.$

Radii of the circles (r), in terms of $(\delta)$, are:

$$
\mathrm{r}=\mathrm{b}\left[1-\left(\delta^{2}\left(\mathrm{a}^{2}-\mathrm{b}^{2}\right) / \mathrm{a}^{2}\left(\mathrm{a}^{2}-\mathrm{c}^{2}\right)\right)\right]^{1 / 2}
$$

Employing these circular sections, the graphical representation of the model produces the foot points $\mathrm{P}_{1}$ and $\mathrm{P}_{2}$. This may be practiced using the auxiliary orthogonal projection (Mongean Projection) of the circular sections onto an auxiliary plane parallel to the circles' planes (Figure 5). In such projection, the circles are projected as circles and, consequently, the projection of any line normal to any circle is projected as the line joining the projection of $\mathrm{E}\left(\mathrm{E}_{1}\right.$ or $\left.\mathrm{E}_{2}\right)$ and the projection of the center of the circle. The line joins points of intersection of the normals to the circles are a curve $\mu$ and $\eta$ (Figure 5).

Obviously, intersection of the two locii of all normals to the two sets of circular sections, i. e., $\mu$ and $\eta$, yields $P_{1}$ and $P_{2}$ and, consequently, $\mathrm{EP}_{1}$ and $\mathrm{EP}_{2}$ are the normals from $\mathrm{E}$ to the surface. Substituting coordinates of $\mathrm{P}_{1}$ and $\mathrm{P}_{2}$ in "3" gives the two real roots of the polynomial. Either $\mathrm{P}_{1}$ or $\mathrm{P}_{2}$ is related to the minimum distance from the terrain point $E$ to the surface, i.e. the geodetic height.

\section{Restrictions for Applicability}

The above illustrated analysis is applicable only for the desired conditions of " 1 ". These conditions arose according to the mutual

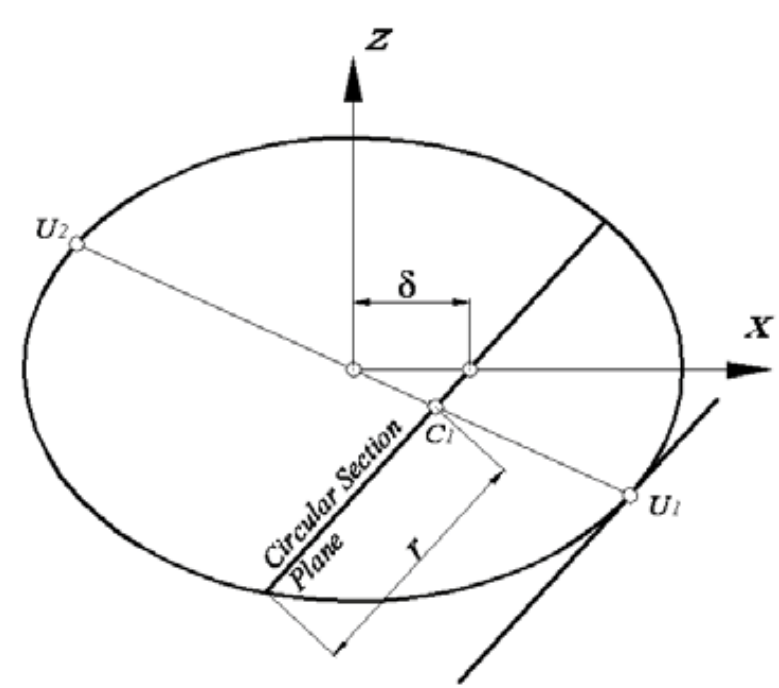

Figure 4: Centre $C_{1}$ and Parameter $\delta$.

relation between size of the surface and the polynomial coefficients.

These conditions may be formulated from " 6 " to "12" as:

$$
\begin{aligned}
& \mathrm{a}_{6}=1 \\
& -4<\mathrm{a}_{5}<0 \\
& \mathrm{a}_{1}>0 \\
& \mathrm{a}_{0}<0 \\
& \mathrm{a}_{0} / \mathrm{a}_{1}>\mathrm{a}_{5} / 16 \\
& -1-\mathrm{a}_{5} / 2<\mathrm{a}_{0} \mathrm{a}_{5} / \mathrm{a}_{1}<\mathrm{a}_{5}{ }^{2} / 16 \\
& \mathrm{a}_{4}<\mathrm{a}_{1}{ }^{2} /\left(\mathrm{a}_{0} \mathrm{a}_{5}{ }^{2}\right)+\left(\mathrm{a}_{5}{ }^{2} / 4\right)+\left(2 \mathrm{a}_{0} \mathrm{a}_{5} / \mathrm{a}_{1}\right) \\
& \mathrm{a}_{2}=\left(3 \mathrm{a}_{1} / \mathrm{a}_{5}\right)+\left(3 \mathrm{a}_{0}{ }^{2} \mathrm{a}_{5}{ }^{2} / \mathrm{a}_{1}{ }^{2}\right)-\left(\mathrm{a}_{0} \mathrm{a}_{4} \mathrm{a}_{5} / \mathrm{a}_{1}\right)+\left(\mathrm{a}_{3} \mathrm{a}_{5} / 4\right)
\end{aligned}
$$




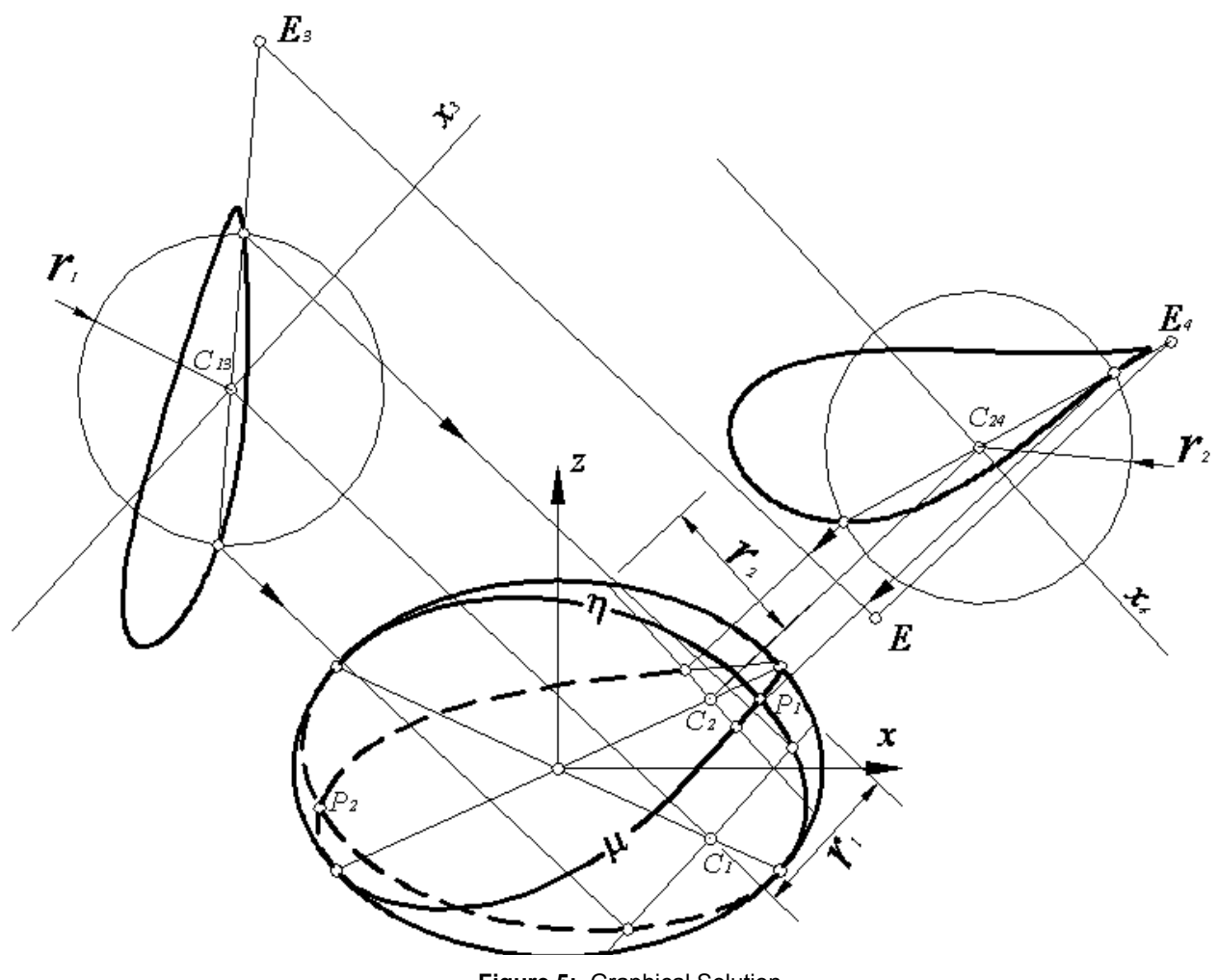

Figure 5: Graphical Solution

Now, we conclude the process as:

1) Verifying conditions (Equation "35").

2) Supposing a reasonable value for $a$.

3) Calculating $\varepsilon$; b; c; F; G and H from "21"; "16"; "17"; "18"; "19" and "20" respectively.

4) Calculating $X_{E}$; $Y_{E}$ and $Z_{E}$ from "13"; "14" and "15" respectively.

5) Constructing Mongean Projection and getting the coordinates of the trace $\mathrm{P}_{1}$ and $\mathrm{P}_{2}$.

6) Substituting coordinates of $\mathrm{P}_{1}$ and $\mathrm{P}_{2}$ in "3" to get the two real roots of "1".

\section{Results}

We introduce a numerical example for the purpose of assessing the applicability of the procedure and verifying its accuracy. Consider the polynomial equation:

$t^{6}-1.74 t^{5}-1.2695 t^{4}+3.064728 t^{3}-1.7921016 t^{2}+0.46002816$ $\mathrm{t}-0.048540902=0$

The first step is checking the coefficients whether they satisfy conditions in "35" or not, where:

$$
\begin{aligned}
& \mathrm{a}_{6}=1 \\
& -4<\left(\mathrm{a}_{5}=-1.74\right)<0 \\
& \left(\mathrm{a}_{1}=0.46002818\right)>0 \\
& \left(\mathrm{a}_{0}=-0.0485409024\right)<0
\end{aligned}
$$

$$
\begin{aligned}
& \left(\mathrm{a}_{0} / \mathrm{a}_{1}=-0.1055172405\right)<\left(\mathrm{a}_{5} / 16=-0.10875\right) \\
& \left(-1-\mathrm{a}_{5} / 2=-0.13\right)<\left(\mathrm{a}_{0} \mathrm{a}_{5} / \mathrm{a}_{1}=0.1835973508\right)<\left(\mathrm{a}_{5}{ }^{2} / 16=0.189225\right) \\
& \left(\mathrm{a}_{4}=-1.2695\right)<\left(\mathrm{a}_{1}{ }^{2} /\left(\mathrm{a}_{0} \mathrm{a}_{5}{ }^{2}\right)+\left(\mathrm{a}_{5}{ }^{2} / 4\right)+\left(2 \mathrm{a}_{0} \mathrm{a}_{5} / \mathrm{a}_{1}\right)=-0.4995000133\right) \\
& \mathrm{a}_{2}=\left(3 \mathrm{a}_{1} / \mathrm{a}_{5}\right)+\left(3 \mathrm{a}_{0}{ }^{2} \mathrm{a}_{5}{ }^{2} / \mathrm{a}_{1}{ }^{2}\right)-\left(\mathrm{a}_{0} \mathrm{a}_{4} \mathrm{a}_{5} / \mathrm{a}_{1}\right)+\left(\mathrm{a}_{3} \mathrm{a}_{5} / 4\right)=-1.7921016
\end{aligned}
$$

Obviously, the coefficients satisfy the conditions, so we move to the second and third step, as we adopt 10 units for the value of a, and using "21"; "16"; "17"; "18"; "19" and "20", then:

$$
\begin{aligned}
\varepsilon & =0.075 \\
b & =8 \\
c & =7
\end{aligned}
$$

Then the fourth step is calculating the terrain point $\mathrm{E}\left(\mathrm{X}_{\mathrm{E}}, \mathrm{Y}_{\mathrm{E}}, \mathrm{Z}_{\mathrm{E}}\right)$ using "13"; "14" and "15" respectively, as:

$$
\begin{aligned}
& X_{E}=12 \\
& Y_{E}=10 \\
& Z_{E}=8
\end{aligned}
$$

The next step is the construction of Mongean graphical technique (Figure 5), in order to obtain the coordinates of the trace $\mathrm{P}_{1}$ and $\mathrm{P}_{2}$. Using the values calculated above, the elements could be plotted using a triaxial ellipsoid model of dimensions a, b and c equal 10, 8 and 7 units respectively. The technique produces two locii $\mu$ and $\eta$ which intersect at $\mathrm{P}_{1}$ and $\mathrm{P}_{2}$, whose coordinates are:

$$
\begin{aligned}
& \mathrm{P}_{1}(6.84,4.59,3.51) \\
& \mathrm{P}_{2}(-8.45,-3.60,-2.03)
\end{aligned}
$$


The final step is the determination of the desired real roots $\left(t_{1}, t_{2}\right)$ of the proposed polynomial by substituting coordinates of $\mathrm{P}_{1}$ and $\mathrm{P}_{2}$ into " 3 ", then we obtain: $t_{1}=1.7540406851$ and

$$
\mathrm{t}_{2}=-1.4202492291 \text {. }
$$

Many geodetic applications engage high accuracy as in analyzing the earth's crustal movements, militant activities, satellite observations, etc. $[6,7]$.

Thus, the significance of the proposed analysis is evaluated versus accuracy, as we apply the values of both $t_{1}$ and $t_{2}$ to the proposed sextic polynomial. The outputs are errors of values $4.1229 \times 10^{-8}$ and $3.3855 \times 10^{-7}$ which may be accepted in the favor of the graphical solution.

Finally, the solution enables getting the shortest distance $\mathrm{EP}_{1}$ from $\mathrm{E}$ to the surface (geodetic height), (Figure 5) which equals 8.7208829828 units.

\section{Discussion}

Polynomial equations of degree higher than the fourth cannot be solved in radicals [2] except Kulkarni decomposition approach, furthermore, sextic polynomials are barely solvable analytically [5].

As the numerical methods are considered as the regular approach for handling the solvable sextic polynomials, they lack the initial guess required for setting up the solution. So, algorithm has to be adapted in order to isolate intervals for the real roots, roughly approximated values of the real roots are calculated then iterations are dealt with using appropriate convergent iteration algorithm, such as Newton method, in order to calculate such roots $[9,10]$. Furthermore, Newton's method for solving higher order polynomials will always converge if the initial point is sufficiently close to the root and if this root is not singular [11].

While Kulkarni introduced an analytical approach, yet the method is limited for the reducible sextic over the real field by the mean of decomposition [12].

Although the offered analysis conveys graphical involvement, it may be considered simple and straightforward method for computing the two real roots of the sextic polynomial. The results show an acceptable accuracy since the errors yielded are of values $4.1229 \times 10^{-8}$ and $3.3855 \times 10^{-7}$ for each root.

In addition, the analysis attends the geodetic height or the shortest distance from a given point to the triaxial ellipsoid surface (as an earth's model) avoiding the engagement of solving system of nonlinear equations using iteration solution scheme produced by Bektas [13].

\section{Conclusions}

Under certain conditions, a sextic polynomial equation of two real roots can be modeled as a familiar geodetic problem which is the geodetic height determination. The triaxial ellipsoidal surface is considered as the surface represents the earth's irregular surface. Surface's parameters and position of the terrain point are evaluated in terms of the polynomial's coefficients, and vice versa.

Graphical solution is carried out for determining two foot points of the normal from a given point to the surface. Such points involve the desired roots and one of them associates the geodetic height.

Numerical justification for examining the approach was introduced and showed a reasonable accuracy versus the graphical solution.

\section{References}

1. Dickenstein A, Emiris LZ (2005) Solving Polynomial Equations-Foundations, Algorithms and Applications. Springer verlag, Germany.

2. King BR (1996) Beyond the Quartic Equation. Birkhauser, Boston.

3. Kulkarni RG (2006) A versatile technique for solving quintic equations. Math Comput Educ 40: 205-215.

4. Weisstein EW (2015) Sextic equation, WolframMathWorld.

5. Kulkarni RG (2008) Solving sextic equations. Atlantic Electr J Math 3: 56-60.

6. Shebl SA (1995) Conformal mapping of the triaxial ellipsoid and its applications in geodesy. Department of Engineering Mathematics and physics, Faculty of Engineering, Alexandria University, Egypt.

7. Snyder JP (1985) Conformal mapping of the triaxial ellipsoid. Survey Rev 28 130-148.

8. Dresden A (1946) Solid Analytical Geometry and Determinations. John Wiley and Sons, New York.

9. Wang L, Wank K, Zhou Z, Cui C (2011) Numerical methods for solving high order polynomial equations. Proceedings of the $4^{\text {th }}$ International Conference on Information and Computing, Phuket Island, Thailand 150-153.

10. Kalban K, El-Hajj A, Khoury S, Yousuf F (2002) Root Computations of Realcoefficient Polynomials using Spreadsheets. Int J Engng, Great Britain 18: 89-97.

11. Sebah P, Gourdon X (2001) Newton's Method and High Order Iterations.

12. Kulkarni RG (2008) Sextics by Division Method. The Teaching of Mathematics 11: 93-96.

13. Bekats S (2014) Shortest Distance from a Point to Triaxial Ellipsoid International Journal of Engineering and Applied Sciences 4. 